\title{
BIG DATA IN HIGHER EDUCATION: ADJUNCT FACULTY PERCEPTIONS OF LEARNING ANALYTICS AND THEIR USES
}

\author{
Denise Bollenback, Embry-Riddle Aeronautical UniversityWorldwide, bollenbd@erau.edu \\ Aaron Glassman, Embry-Riddle Aeronautical University Worldwide, glassf10@erau.edu
}

\begin{abstract}
Universities are adopting business analytics style approaches to student, faculty, course, and program performance data in an effort to respond to the needs of internal and external stakeholders. The analytics approach is more commonly known in higher education as a learning analytics strategy which focuses on leveraging existing enterprise information systems used within the university to provide insights on student learning and predict learner's behavior through data visualization and analytics techniques. Education Technology (EdTech) companies are now creating integrations to simplify some of these analytics processes and make their use more faculty friendly however some universities have identified challenges when implementing these strategies. The specific challenges that geographically distributed, higher education institutions that rely heavily on adjunct faculty face do not appear well understood in the existing literature. In this research, we determined the perceptions of adjunct faculty in adopting learning analytics technologies across a distributed network. It was discovered what while most faculty are ready with the proper training to embrace such a platform, some very real concerns exist in how learning analytics data would be used by university administration and beyond. The creation of specific acceptable use policies for analytics data maybe one solution to addressing those concerns.
\end{abstract}

Keywords: Learning Analytics, Analytics, Faculty Perceptions, Big Data, Learning Management Systems, Online Learning

\section{INTRODUCTION}

Many universities are now customizing their course delivery methods and instructional designs (e.g., blended learning, hybrid online, etc.). The United States Department of Education (DOE) has taken a keen interest in reporting student performance to make sure these new methods and designs are academically sound (Johnson, Becker, Estrada, \& Freeman, 2014). As the design of distance education courses constantly evolves, the need to provide visual representation (e.g., infographics) of learner performance as well as comprehensive, longitudinal analysis will become more important. Learning analytics strategies will need to be developed to allow institutions to make well informed decisions using different performance metrics generated from both descriptive and predicate analytics tools. Having the ability to provide accurate and consistent student learning and performance data will also provide the institution with a competitive advantage by monitoring the levels of achievement of the course, program, student and faculty. This new information will also contribute to a model of adaptive learning by analyzing student behaviors to provide a custom, student-level experience so that the learning space adapts to each learner's needs (US Dept. of Education, 2017). The US Department of Education has mentioned adaptive learning many times in an effort to make education learned-centered. However, it's unclear whether or not our educational system and each stakeholder is prepared for this paradigm shift where near real-time analytics data will drive the teaching and learning process.

In order for a university to benefit from data mining, the university must be willing to invest the labor hours to align learning outcomes at the course level, program level and even between other, like institutions. Alignments between different types of assessment activities and student learning outcomes provide the infrastructure to allow data to be collected within a geographically distributed environment (e.g., those with a large online learning footprint). Creating this connection through various instructional technologies, student learning can be analyzed at any level within the institution and ultimately across higher education. Learning analytics strategies, if focused on pedagogy and industry standard alignments, may also contribute to a large-scale needs assessment. These data would identify needs and gaps between the educational institution and the employers looking to hire graduates and serve as a point of feedback to the institution on how to better prepare graduates for the workforce (Gasevic, 2018). 


\section{Issues in Information Systems \\ Volume 19, Issue 3, pp. 71-80, 2018}

In addition to gaining a better understanding of program-specific data and alignment to industry standards, learning analytics strategies would also be of benefit to constituents responsible for reporting program level findings and results within academic assessment plans. Faculty responsible for collecting these data face many challenges in assessing massive amounts of courses and course sections. Fontenot (2012) found that faculty in general were frustrated with responsibilities pertaining to assessment processes due to the amount of time and effort needed to collect, analyze and report assessment findings. The amount of effort needed to obtain information requested by various accreditation bodies, administration, and review boards could be dramatically decreased with a proven learning analytics strategy and systematic approach to assessment processes.

\section{LITERATURE REVIEW}

One of the main technologies used for managing distance learning courses is the learning management system (LMS). Many higher education institutions have adopted LMSs; however, negative faculty perceptions of LMSs decreases the potential for a system-wide approach to implementing a learning analytics strategy. To collect data regarding student behaviors or learning patterns electronically, faculty would need to use a variety of information systems whereby the students submit their work through the information system for continuous feedback as well as grading. In the Educause ECAR Study of Faculty and Information Technology (Pomerantz \& Brooks, 2017), the specific brand of LMS that is implemented at an institution has little impact on faculty members' use of it or their satisfaction with that use. In other words, the challenges each university face are not platform specific.

Martin and Sherin (2013) provided several examples of ways in which to sample, capture, reduce, and find patterns using an analysis of collected data throughout various instructional technologies used, such as the learning management system, social media, digital portfolios, and e-books. Simulation and gaming software is also being researched to determine how student actions are related to learning outcomes. This is usually referred to as stealth assessment. Shute, Ventura, and Kim (2013) describe stealth assessment as an approach using evidence directly within the learning environment with little faculty participation. As students interact with a gaming interface, their actions and interactions with other students are recorded and used to demonstrate whether they have met the student learning outcomes (Shute, Ventura, Small, \& Goldberg, 2013).

Gasevic, Dawson, and Siemens (2015) explained the need for instructional design policies and cultures to support the advancement of better understanding the learning process and the internal and external conditions as opposed to automating the measurement of learning outcomes. They explained several lessons learned from case studies in which learning analytics were used for various purposes, such as student retention and student learning outcomes measurement and noted the need for more research in the field of learning analytics to support learning conditions and the learning and teaching process. Liu and Koedinger (2017) reviewed cognitive models as a method of providing a foundation for instructional design of automated course deliveries and accurate assessment of learning. In addition, research in learning design has supported the need for improving learning design techniques and teacher inquiry through the use of learning analytics (Persico \& Francesca, 2015).

With the increased use of educational technology and developing multiple methods of delivering instruction in higher education, universities continue to find ways to assess student learning through systematic approaches for both summative and formative assessment. Formative assessment focuses on learning and provides continuous and immediate feedback with evidence to support ongoing improvement based on feedback, while summative assessment focuses on validation and accreditation (Gikandi, Morrow, \& Davis, 2011). Formative assessment using educational technology in both blended and online modalities provides opportunities for immediate feedback and ways to collect evidence electronically. The National Education Technology Plan from the US Department of Education addresses the use of technology in assessment as well. The plan identified the potential for instructors to address student misconceptions at that point within the course (US Dept. of Education, 2017). To assist with the various challenges of using data effectively and appropriately for assessment, the National Center for Education Statistics has released a set of Common Education Data Standards.

Leveraging learning analytics to retain students and improve outcomes is of great interest to higher education educators and administrators (Dawson, Jovanovic, Gasevic, \& Pardo, 2017; Dietz-Uhler \& Hurn, 2013; Corrin, Kennedy, \& Mulder, 2013; Smith, Lange, \& Huston, 2012). By analyzing student activity through the LMS, educators 


\section{Issues in Information Systems \\ Volume 19, Issue 3, pp. 71-80, 2018}

can gain insight into student behaviors within the online environment. For example, Andergassen, Modritscher, and Neumann (2014) identified student behaviors through analyzing log data within the LMS and found a positive correlation between practice and repetition and final exam grades. Picciano (2014) identified many of the benefits and concerns of using learning analytics in blended environments, explaining there may be gaps where the learning system might have been used in different ways creating incompatible or difficult to analyze data sets. The use of the LMS should be consistent, as the same types of activities can produce rubric statistics reports to track learning outcome achievement at any level within the institutional hierarchy.

As students submit online course activities and the activities are graded, a trail of evidence of student performance is created (Becker, Cummins, Davis, Freeman, Hall, \& Ananthanarayanan, 2017). There are several data mining and analytics reporting capabilities yet to be explored within a more wide-scale environment across several different modalities of instruction and various course activities and instructional technology implementations. These data are collected and can be used in course performance reports and longitudinal analytics reports showing student performance by learning outcomes at any level within the institutional hierarchy and at any time. Instructors, program chairs, and administrators can all view the report. Bollenback (2015) provided several examples of learning analytics reports used as techniques to measure student learning outcomes. In one report, thousands of graded assessments that were aligned to specific program outcomes were analyzed to determine student achievement levels. The report shows the average student score for course activities aligned to program outcomes. The report can be generated by campus, college, location, assessment type, modality, and program outcome. This report included courses being delivered through five different modalities of instruction in over 150 locations worldwide within a single university system. In addition to the learning analytics report, the Student Performance Reports reveal student performance metrics for specific program outcomes within an individual course as aligned to different types of assessment activities. These are just a few examples of how learning analytics can be leveraged to support academic program assessment.

In addition to using the LMS to collect and report information on student performance, other systems such as the endof-course evaluation systems can be structured in a manner that allows reporting to be tied to program outcomes and industry needs. These reports allow program chairs and department chairs to have a high-level view of the results of the course evaluations for all courses mapped to a program outcome, which is an aggregate view of just one of the survey questions. All questions can be viewed in the same manner throughout the program and as aligned to program outcomes. These learning analytics reports generated through the LMS are not necessarily linked to an approach to teaching and learning and can be used regardless of modality of instruction. The challenges faced now by many institutions involve the need for data compatibility and aggregation between educational technology platforms. There are some communications and data standards such as IMG Global's Learning Tools Interoperability (LTI) standard that do exist but currently no universal standard exists.

Another technique in taking advantage of end-of-course evaluation results is to use data from the question related to if a student would recommend the course to a friend or colleague to calculate the Net Promoter Score (NPS). The Net Promoter Score is used in industry by calculating sections of customer recommendations from surveys (Woodall, Hiller, \& Resnick, 2014). Once the NPS has been calculated for courses aligned to a program, the performance scores as well as pass/fail rates can be combined to establish what could be called 3D analytics. This looks across multiple courses, multiple, sections, and multiple modalities of instruction to examine potential trends throughout the learning analytics models.

While many of the studies presented thus far imply a positive outlook for the use of analytics in education, there are also some opposing views. Dringus (2012) highlighted many areas of concern with the use of learning analytics in online education, explaining that data collected could be misleading and not a true or accurate depiction of the learning that is actually occurring in the online environment. Dringus explained that the data trail often used in analytics may not be a clear picture or provide visual representation of the true performance indicators within an online course. Another perception questioning the use of learning analytics is focused on security and the privacy of student information. Siemens and Long (2011) expressed concern that analytics only show the what and not the why which could be very misleading as well as what behavioral elements were being collected. There are several other risks involved with leveraging student learning data such as lack of faculty and staff training on data interpretation or fears that data could be misinterpreted and lead to improper actions. An acceptable use policy that addresses the universities approach to data management from a faculty and student perspective as well as both the legal and ethical responsibilities associated with data privacy should help address those fears. (Tsai \& Gasevic 2017). 
After reviewing the literature related to faculty adoption of educational technology, various assessment techniques and tools that can be used to assess student learning through various modalities of instruction were identified as valid assessment methods. Although these studies were successful in assessing student learning, many constraints were identified within each study. It appears technology clusters and rate of adoption criteria are beginning to appear in academic analytics research. Rogers (2003) illuminated the use of technology clusters in the diffusion of innovations theory. This is the concept that the adoption of one new idea may spark an adoption of a related new idea through interrelated technologies. The clusters are then presented as a package, which is often a better selling point than a single innovation. Predictive analytics uses this same approach in packaging results from different types of systems used in academics to predict teaching and learning patterns and provide early warning to at-risk students. Exposing the constraints, perceptions, and barriers associated with learning analytics will allow additional research to foster an environment of continuous improvement, improve adoption rates by faculty, and guide the educational technology sector in how to improve product sales and speed implementation.

\section{RESEARCH METHODOLOGY}

A concurrent mixed-methods approach (Creswell, 2009) was used to understand the perceptions of faculty as it relates to learning analytics. The survey instrument (see Appendix A) contains closed-ended, quantitative questions in addition to an open-ended, qualitative element. This mixed-methods approach provides the researchers with insight into specific faculty preferences (quantitative) in addition to rich, detailed, discussion as to why one might choose those preferences (qualitative). The goal of this particular methodology is to understand the following:

\section{Research Question:}

How do faculty perceive the uses of learning analytics concepts as it relates to their desire to use learning analytics within their course and program.

\section{Hypothesis:}

H1: There will be a faculty preference as it relates to (statements regarding learning analytics).

H0: There will not be a faculty preference as it relates to (statements regarding learning analytics).

\section{Propositions:}

P1: Faculty will see the value in having a learning analytics strategy as a tool to enhance their classroom capabilities.

\section{Participants}

The survey participants consisted of all Embry-Riddle Aeronautical University - Worldwide adjunct faculty who are approved to teach undergraduate business (MGMT prefix) courses. Adjunct faculty were selected as a population since they are the most likely to come in contact with learning analytics tools at the course level. This subset of the entire adjunct population was chosen since it is mostly representative of the adjunct population at Embry-Riddle Aeronautical University - Worldwide. Most faculty are approved to teach in different colleges in addition to different courses within each college. Based on the nature of the adjunct population, the anticipated response rate was $15 \%$ which would result in 133 expected responses from the population subset of 889 faculty. This sample size should be adequate to generalize from and represent the population from which it was drawn.

\section{Survey Instrument \& Precautions}

A mixed-methods survey instrument was developed using Likert-style questions in addition to open-ended questions (Bradburn, Sudman, \& Wansink, 2004). Demographics questions were included to see if any specific answer patterns could be cross-tabulated with any particular faculty demographic. A panel of experts was used to determine face validity of the instrument and feedback and refinements from the panel of experts was considered and adjustments made prior to disseminating the final instrument (Saunders, Lewis, \& Thornhill, 2009). In addition, the panel of experts provided input on internal validity of the instrument (content, criterion, and construct) and adjustments were made here as well.

The survey instrument was built and hosted online using SurveyMonkey. SurveyMonkey was configured so that all responses are anonymous in that no identifying data, including IP addresses, was collected. Although responses were 
anonymous, there is the possibility that identifying information may be included in open-ended questions. When identifying data was present, a single researcher de-identified the responses before sharing the data file with the research team.

\section{Procedure}

The researchers solicited participation from the targeted faculty through an initial contact e-mail sent to each faculty member's university e-mail address. The survey instrument was accessed via a web link contained in the initial contact e-mail and directed the respondent to the survey instrument in SurveyMonkey. A second reminder e-mail was sent 710 days after the initial contact e-mail was sent with a total response period of 2 weeks. Once the data was collected, the coded quantitative data was initially analyzed using descriptive statistics and infographics. A Chi-square test was also used to determine statistical significance of the response patterns to ensure the patterns were not random or distributed by chance. The qualitative data was reviewed in narrative detail and then coded to identify common themes.

\section{RESEARCH RESULTS}

This survey resulted in a 113 usable adjunct faculty responses. There were known limits to the population that likely affected the response rate such as the number of faculty teaching that term who were likely to check their email. Adjunct faculty who have not taught in several terms were less likely to respond to emails sent to their university email address. Therefore, a $n=113$ was considered good response rate just below the target response rate. Of those who responded 50\% taught undergraduate courses, $23 \%$ taught graduate courses, and $27 \%$ taught both undergraduate and graduate courses. A chi-square test indicated that none of the responses were random distributions.

\section{Demographics/Computer Literacy}

Faculty age was normally distributed with the bulk of the faculty clustered around the 45-65 age range (equal distribution in the 45-54 and 55-64 age bins). Although not a surprise based on self-selection of faculty who choose to teach online, the vast majority of faculty felt comfortable with computers $(92 \%, n=104)$. The majority of faculty, or $87 \%(n=97)$ knew many advanced software features in the platforms they use and $86 \%(n=97)$ were comfortable learning new software or using new computers. This data was obtained to rule out any improper influence of computer or software literacy in the faculty responses. Based on this data, it could be said that faculty have the skills and abilities to needed to use learning analytics in their courses.

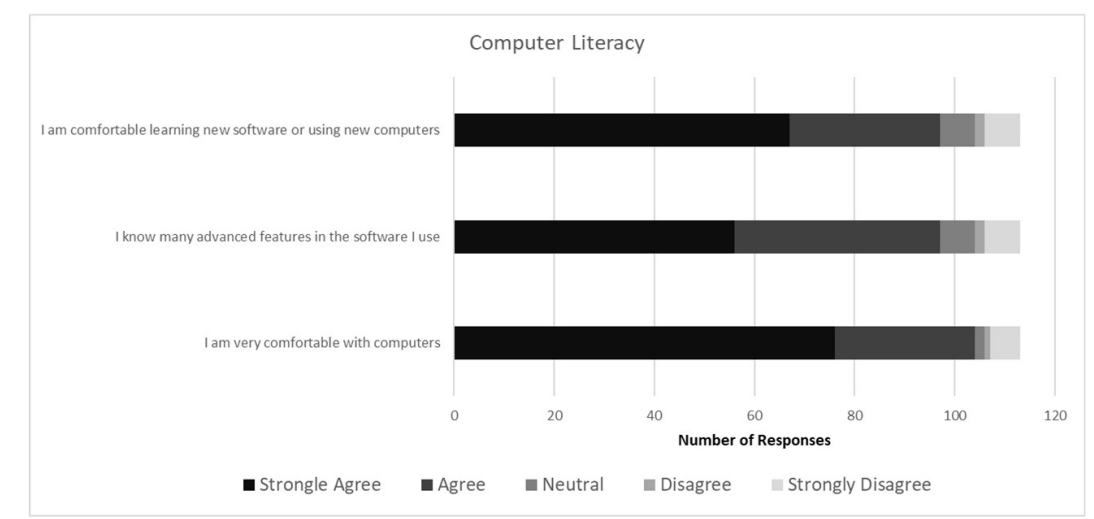

Figure 1. Self-report measure of faculty computer literacy

\section{Analytics Uses}

When asked questions specific to learning analytics, the results were generally positive. The majority of faculty agreed that learning analytics should be used by course developers to monitor how faculty achieve the learning outcomes and adjust as necessary $(83 \%, n=94)$. The same agreement exists as it relates to receiving feedback on student learning outcome achievement $(90 \%, \mathrm{n}=102)$. The agreement lessened when faculty felt learning analytics was being used as a tool to monitor their classroom performance. Only $62 \%(n=70)$ of faculty agreed that faculty performance reviews should contain data on how well a student performed against a learning outcome. Faculty 
were also less interested in using analytics data to compare their performance with other faculty teaching the same course; only $68 \%(n=77)$ thought this was a good idea.

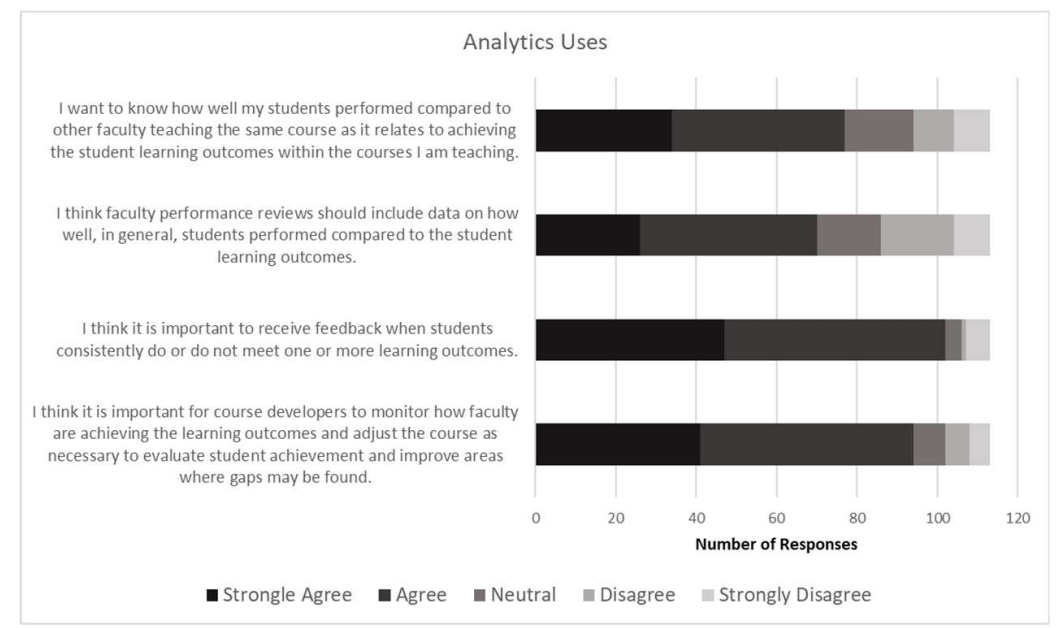

Figure 2. Faculty responses to analytics uses

\section{Analytics Adoption}

In general, $74 \%(\mathrm{n}=84)$ agreed that learning analytics had value but this question had a high percentage of faculty who were uncertain, or $22 \%(n=25)$. The majority of faculty, $73 \%(n=81)$ felt that if they had the proper training they would use learning analytics within their courses. A two-factor ANOVA identified a statistically significant difference between age and learning analytics use. Faculty who were 35-44 years old and 55-64 years old were 69\% likely to agree or strongly agree whereas faculty who were $45-54$ years old were $81 \%$ likely to agree or strongly agree and faculty who were 55-64 years old were $72 \%$ likely to agree or strongly agree.
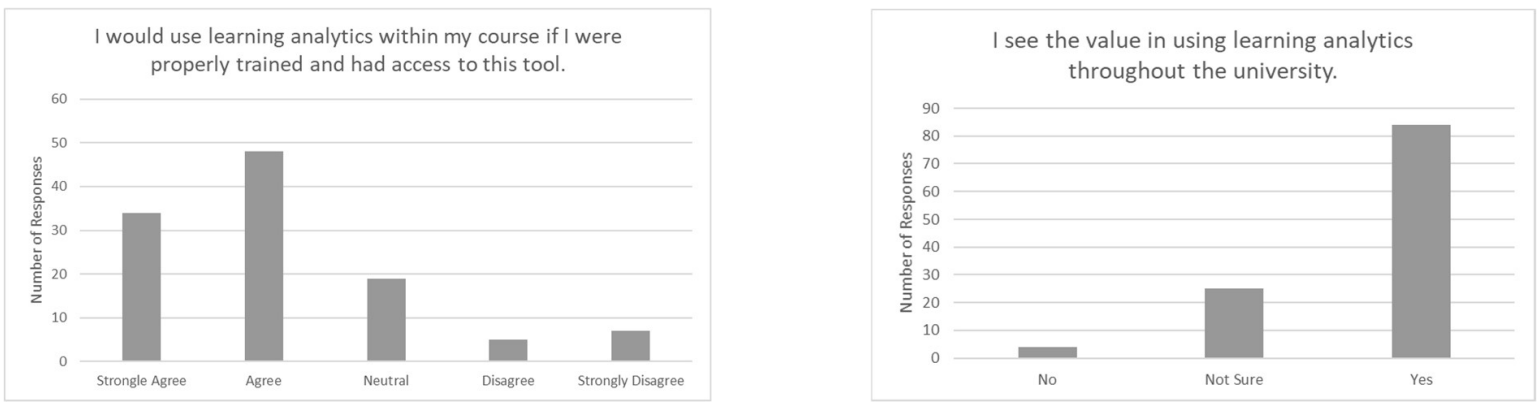

Figure $3 \&$ 4. Learning analytics use and value

The following constructs emerged when the qualitative data was thematically cataloged and example response from each theme were reviewed:

Faculty thought that 1) learning analytics would provide good data for the university, 2) improve individual faculty performance, 3) provide evidence of LO attainment to accreditors, however faculty were concerned about 4) how the data would be used, 5) whether they would be unfairly identified as "bad" if their students struggled to meet LO's (in the context of faculty who teach hard classes). Some faculty feedback fell into multiple theme categories and is represented here (table 1).

Table 1. Theme and frequency

\begin{tabular}{|l|l|l|l|}
\hline Theme & Frequency & Theme & Frequency \\
\hline Provides Additional Measurable Data & 32 & $\begin{array}{l}\text { Improves Individual Faculty } \\
\text { Performance }\end{array}$ & 17 \\
\hline Concerns About Use/Implementation & 27 & Evidence of LO Attainment & 9 \\
\hline
\end{tabular}




\section{SUMMARY}

This research is significant in that the Educational Technologies (EdTech) market is growing rapidly to assist universities in the management of their data. The need for these solutions is being driven by higher education accreditation mandates and universities will need to embrace these solutions. LMS's are now generating a substantial amount of data that can be analyzed to determine the performance of the faculty, student, course, program, and beyond. However useful the technology may be, the acceptance of learning analytics technologies and their uses must first be embraced by the faculty. There were some legitimate concerns expressed that must be addressed such as the perceived "big brother" aspect of analytics and the mis-use of aggregate results as it relates to faculty performance. An acceptable use policy that outlines specific uses for each data set and associated technology as well as administrative use transparency may help address these concerns. The narrative themes and survey responses do affirm that faculty remain committed to using data to develop better courses, improve their teaching abilities, and welcome an early warning dashboard when students may be at risk. A multi-university survey or larger sample size would further validate or enhance the results of this study.

Faculty are key in implementing a learning analytics strategy (Corrin, Kennedy, \& Mulder, 2013) since they are the end user of this new information system and analytics capability. The results presented here could also be generalized to institutions as a means to plan for a successful learning analytics implementation. Finally, the role of data cannot be underestimated. Universities are generating a substantial amount of data, entire EdTech companies are being born around how to manage, analyze, and utilize this data, with the ultimate goal of ensuring that big data doesn't become data waste. In an era where student learning must be measured and more frequently aligned with industry needs, a sound learning analytics strategy is a must as well as buy-in from the faculty who make up the future end-users of such a platform.

\section{REFERENCES}

Andergassen, M., Mödritscher, F., \& Neumann, G. (2014). Practice and repetition during exam preparation in blended learning courses: Correlations with learning results. Journal of Learning Analytics, 1(1), 48-74.

Becker, S. A., Cummins, M., Davis, A., Freeman, A., Hall, C. G., \& Ananthanarayanan, V. (2017). NMC horizon report: 2017 higher education edition (pp. 1-60). The New Media Consortium.

Bollenback, D. (2015, December). A Learning Analytics Approach to Academic Program Assessment in Higher Education. Distance Learning, 12(3), 29-36.

Bradburn, N. M., Sudman, S., \& Wansink, B. (2004). Asking questions: The definitive guide to questionnaire design: For market research, political polls, and social and health questionnaires (Rev ed.). San Francisco: Jossey-Bass. Retrieved from http://www.loc.gov/catdir/toc/ecip0413/2004001683.html

Corrin, L., Kennedy, G., \& Mulder, R. (2013). Enhancing learning analytics by understanding the needs of teachers. Retrieved from: http://www.ascilite.org/conferences/sydney13/program/papers/Corrin.pdf

Creswell, J. W. (2009). Research design: Qualitative, quantitative, and mixed methods approaches (3rd ed.). Thousand Oaks, Calif.: Sage Publications.

Dawson, S., Jovanovic, J., Gašević, D., \& Pardo, A. (2017, March). From prediction to impact: Evaluation of a learning analytics retention program. In Proceedings of the Seventh International Learning Analytics \& Knowledge Conference (pp. 474-478). ACM.

Dietz-Uhler, B., \& Hurn, J. E. (2013). Using learning analytics to predict (and improve) student success: A faculty perspective. Journal of Interactive Online Learning, 12(1), 17-26.

Dringus, L. P. (2012). Learning Analytics Considered Harmful. Journal of Asynchronous Learning Networks, 16(3), 87-100. 


\section{Issues in Information Systems}

Volume 19, Issue 3, pp. 71-80, 2018

Fontenot, J. (2012). Faculty concerns about student learning outcomes assessment. [National Institute for Learning Outcomes Assessment Web log comment]. Retrieved from http://illinois.edu/blog/view/915/76774.

Gašević, D. (2018). Include us all! Directions for adoption of learning analytics in the global south. Learning analytics for the global south, 1-22.

Gašević, D., Dawson, S., \& Siemens, G. (2015). Let’s not forget: Learning analytics are about learning. TechTrends, 59(1), 64-71.

Gikandi, J., Morrow, D., \& Davis, N. (2011). Online formative assessment in higher education: A review of the literature. Computers \& Education, 57(4), 2333-2351. Retrieved from http://dx.doi.org.ezproxylocal.library.nova.edu/10.1016/j.compedu.2011.06.004

Johnson, L., Becker, S., Estrada, V., \& Freeman, A. (2014). Horizon Report: 2014 Higher Education.

Liu, R., \& Koedinger, K. (2017). Going Beyond Better Data Prediction to Create Explanatory Models of Educational Data. The Handbook of Learning Analytics, 69-76.

Martin, T., \& Sherin, B. (2013). Learning Analytics and Computational Techniques for Detecting and Evaluating Patterns in Learning: An Introduction to the Special Issue. Journal of the Learning Sciences, 22(4), 511520.

Persico, D. \& Pozzi, F. (2015), Informing Learning Design with Learning Analytics to improve teacher inquiry. British Journal of Educational Technology, 46: 230-248. doi:10.1111/bjet.12207

Picciano, A. G. (2014). Big data and learning analytics in blended learning environments: benefits and concerns. IJIMAI, 2(7), 35-43.

Pomerantz, J. \& Brooks, D. (2017) ECAR Study of Faculty and Information Technology, 2017. Research report. Louisville, CO: ECAR, October 2017. Retrieved from https://library.educause.edu/ /media/files/library/2017/10/facultyitstudy2017.pdf

Rogers, E. M. (2003). Diffusion of innovations (5th edition). New York, NY: Free Press.

Saunders, M., Lewis, P., \& Thornhill, A. (2009). Research methods for business students (5th ed.). England: Prentice Hall.

Shute, V. J., Ventura, M., \& Kim, Y. J. (2013). Assessment and learning of qualitative physics in newton's playground. The Journal of Educational Research, 106(6), 423-430. doi:10.1080/00220671.2013.832970

Shute, V., Ventura, M., Small, M., \& Goldberg, B. (2013). -Modeling Student Competencies in Video Games Using Stealth Assessment. Design recommendations for intelligent tutoring systems, 1, 141-152.

Siemens, G., \& Long, P. (2011). Penetrating the fog: Analytics in learning and education. Educause Review, 46(5), 30-32.

Smith, V. C., Lange, A., \& Huston, D. R. (2012). Predictive modeling to forecast student outcomes and drive effective interventions in online community college courses. Journal of Asynchronous Learning Networks, 16(3), 51-61.

Tsai, Y., \& Gasevic, D. (2017). Learning analytics in higher education --- challenges and policies: A review of eight learning analytics policies. Paper presented at the 233-242. doi:10.1145/3027385.3027400

US Dept. of Education. (2017). Reimagining the Role of Technology in Education. Washington, DC: Government Printing Office, 2017. Retrieved from https://tech.ed.gov/files/2017/01/NETP17.pdf 


\section{Issues in Information Systems}

Volume 19, Issue 3, pp. 71-80, 2018

Woodall, T., Hiller, A., \& Resnick, S. (2014). Making sense of higher education: Students as consumers and the value of the university experience. Studies in Higher Education, 39(1), 48-67. 


\section{Issues in Information Systems}

Volume 19, Issue 3, pp. 71-80, 2018

\section{APPENDIX A - Survey Instrument}

Note: The introduction, IRB statements, etc. have been removed for brevity. A definition of learning analytics and its scope and scale were included in the survey design to ensure a common definition and intended levels of application were included.

General

1. Faculty Status

Confirming participant is an adjunct

2. What level of course(s) do you teach? Undergraduate/Graduate/Both

3. Age Range 10-year increments

Computer Literacy

4. I am very comfortable with computers Agreement/Likert-Style Scale

5. I know many advanced features in the software I use. Agreement/Likert-Style Scale

6. I am comfortable using new software or using new computers. Agreement/Likert-Style Scale

Learning Analytics Uses

7. I think it is important for course developers to monitor how faculty are achieving the learning outcomes and adjust the course as necessary to evaluate student achievement and improve areas where gaps may be found.

Agreement/Likert-Style Scale

8. I think it is important to receive feedback when students consistently do or do not meet one or more learning outcomes. Agreement/Likert-Style Scale

9. I think faculty performance reviews should include data on how well, in general, students performed compared to the student learning outcomes. Agreement/Likert-Style Scale

10. I want to know how well my students performed compared to other faculty teaching the same course as it relates to achieving the student learning outcomes within the courses I am teaching. Agreement/Likert-Style Scale

Learning Analytics Adoption

11. I see the value in using learning analytics throughout the university. Yes/No/Not Sure + Explain Your Answer (Textbox)

12. I would use learning analytics within my course (see example*) if I were properly trained and had access to this tool.

Agreement/Likert-Style Scale

*An example dashboard image with descriptive and predictive analytics capabilities was included. 